\title{
Volcano Curves for in Silico Prediction of Mono- and Bifunctional Catalysts: Application to Ammonia Decomposition
}

\author{
Hongbo $\mathrm{Wu},{ }^{\dagger}$ Jonathan E. Sutton, ${ }^{\star,}$ Wei Guo, ${ }^{*, \dagger}$ and Dionisios G. Vlachos, ${ }^{*, \S}$
}

${ }^{\dagger}$ Key Laboratory of Advanced Optoelectronic Quantum Architecture and Measurement (MOE), Beijing Key Laboratory of Nanophotonics \& Ultrafine Optoelectronic Systems, and School of Physics, Beijing Institute of Technology, Beijing 100081, People's Republic of China ‡Eastman Chemical Company, Kingsport, Tennessee 37660, United States

${ }^{\S}$ Department of Chemical \& Biomolecular Engineering and Catalysis Center for Energy Innovation, University of Delaware, Newark, Delaware 19716, United States

Table S1. BEP relations between activation energy $\left(E_{\mathrm{a}}\right)$ and reaction energy $\left(E_{\mathrm{rxn}}\right)$ for $\mathrm{NH}_{x}^{*}$ dissociation and $\mathrm{N}^{*}-\mathrm{N}^{*}$ association reactions approximated with $E_{\mathrm{a}}=m E_{\mathrm{rxn}}+n$. Energies are in $\mathrm{kcal} / \mathrm{mol} . \mathrm{H}_{2}$ and $\mathrm{N}_{2}$ adsorptions are treated as barrierless.

\begin{tabular}{cll}
\hline Reaction & $m$ & $n$ \\
\hline $\mathrm{NH}_{3}^{*}$ dissociation & 0.71 & 23.23 \\
$\mathrm{NH}_{2}^{*}$ dissociation & 0.52 & 19.83 \\
$\mathrm{NH}^{*}$ dissociation & 0.29 & 23.75 \\
$\mathrm{~N}_{2}^{*}$ association on terrace & 0.33 & 50.04 \\
$\mathrm{~N}_{2}^{*}$ association at edge & 0.32 & 40.36 \\
\hline
\end{tabular}
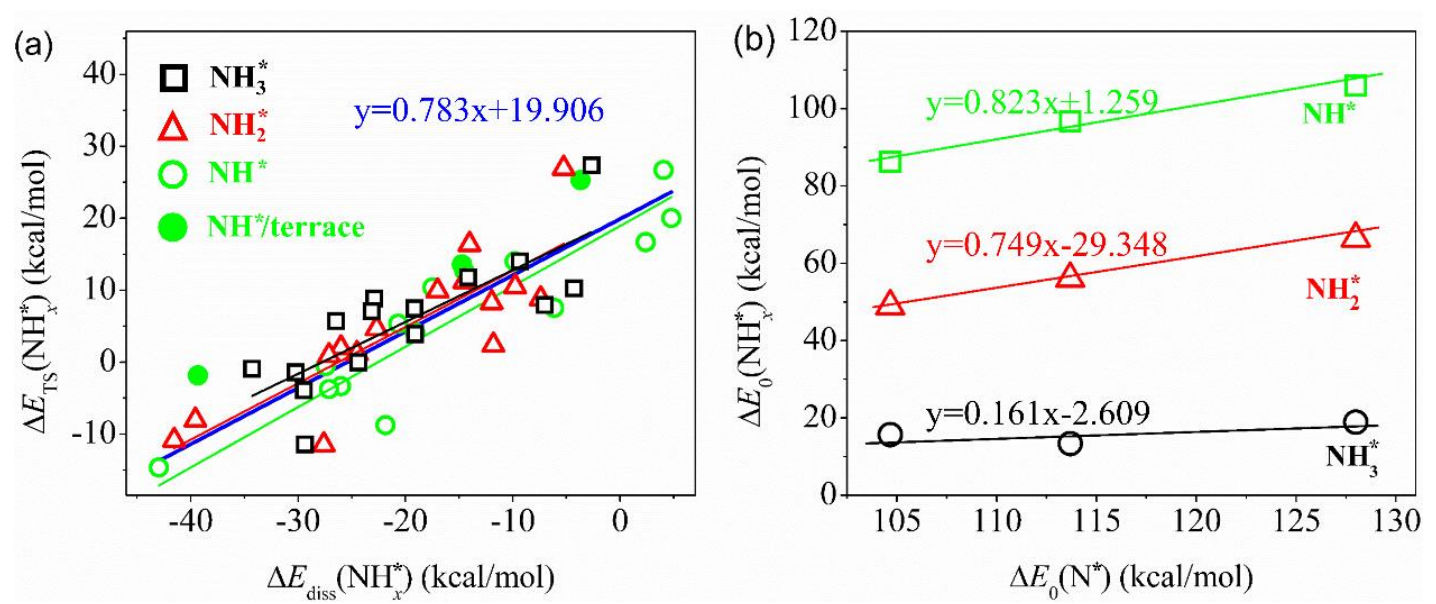

Figure S1. Thermochemical scaling relations (TCSRs) for $\mathrm{NH}_{3}$ decomposition reaction on various transition metal/bimetallic facets. (a) Universal transition state scaling relation (TSSR) between $\Delta E_{\mathrm{TS}}\left(\mathrm{NH}_{x}^{*}\right)$ and $\Delta E_{\text {diss }}\left(\mathrm{NH}_{x}^{*}\right)$ of $\mathrm{NH}_{x}^{*}$ dehydrogenation reactions. The solid symbols in green color are based on our DFT calculations, and the rest of the data is from literature. The blue solid line is the universal TSSR model. $\mathrm{NH}_{3}$ in the gas-phase is used as the reference state. (b) TCSR between $\Delta E_{0}\left(\mathrm{NH}_{x}^{*}\right)$ and $\Delta E_{0}\left(\mathrm{~N}^{*}\right)$ on Ni, Pt and Ni-Pt-Pt terrace sites. The TCSRs of $\mathrm{NH}$ and $\mathrm{NH}_{2}$ agree well with previous literature ${ }^{1}$, and the $\mathrm{NH}_{3}$ scaling is based on our own published DFT data ${ }^{2}$. 

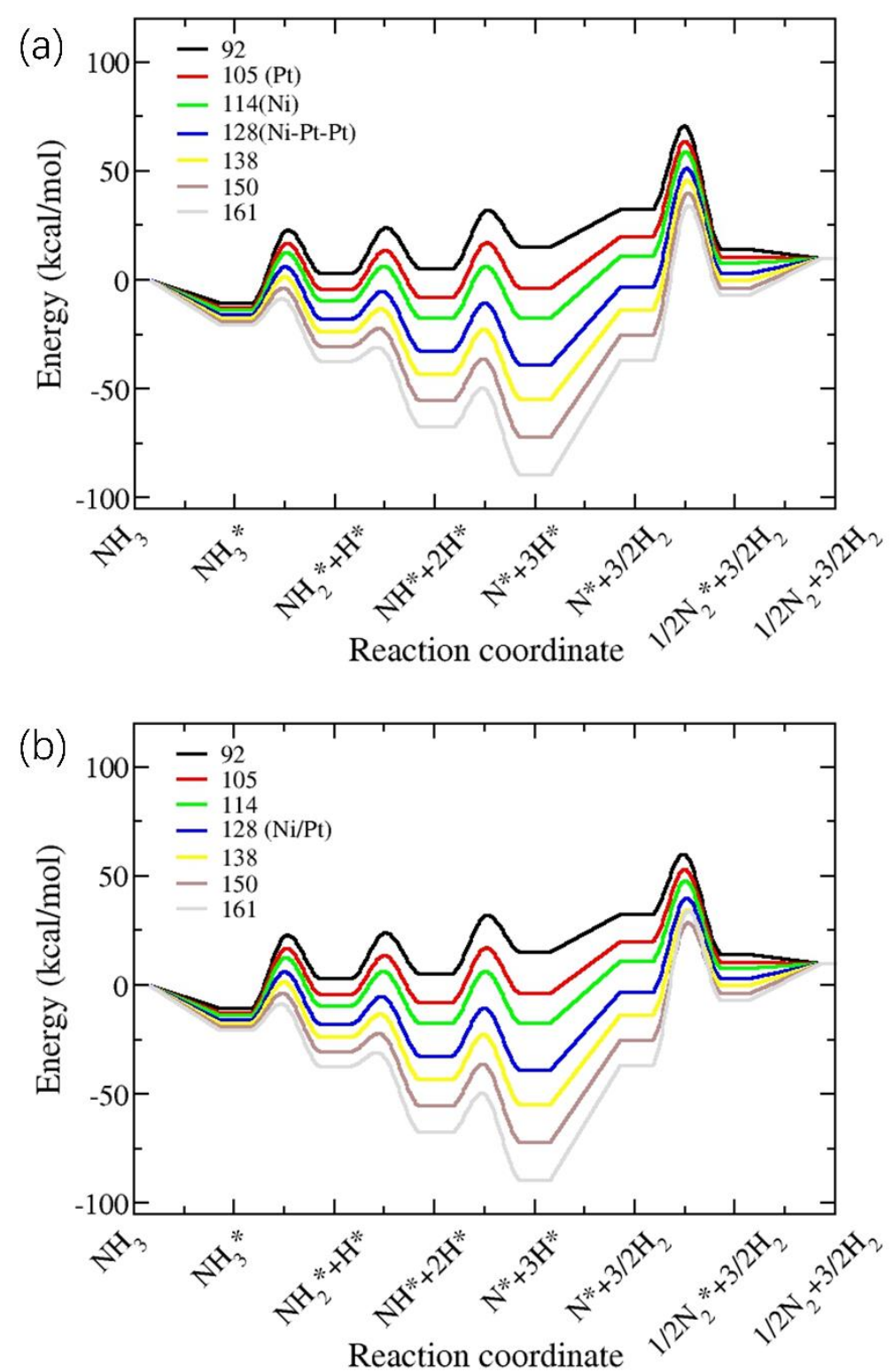

Figure S2. Energy profiles calculated with TCSR and TSSR as input (a) for perfect and (b) defected surfaces. The numbers in the legend indicate the value of $\Delta E_{0}\left(\mathrm{~N}^{*}\right)$ on each surface. 

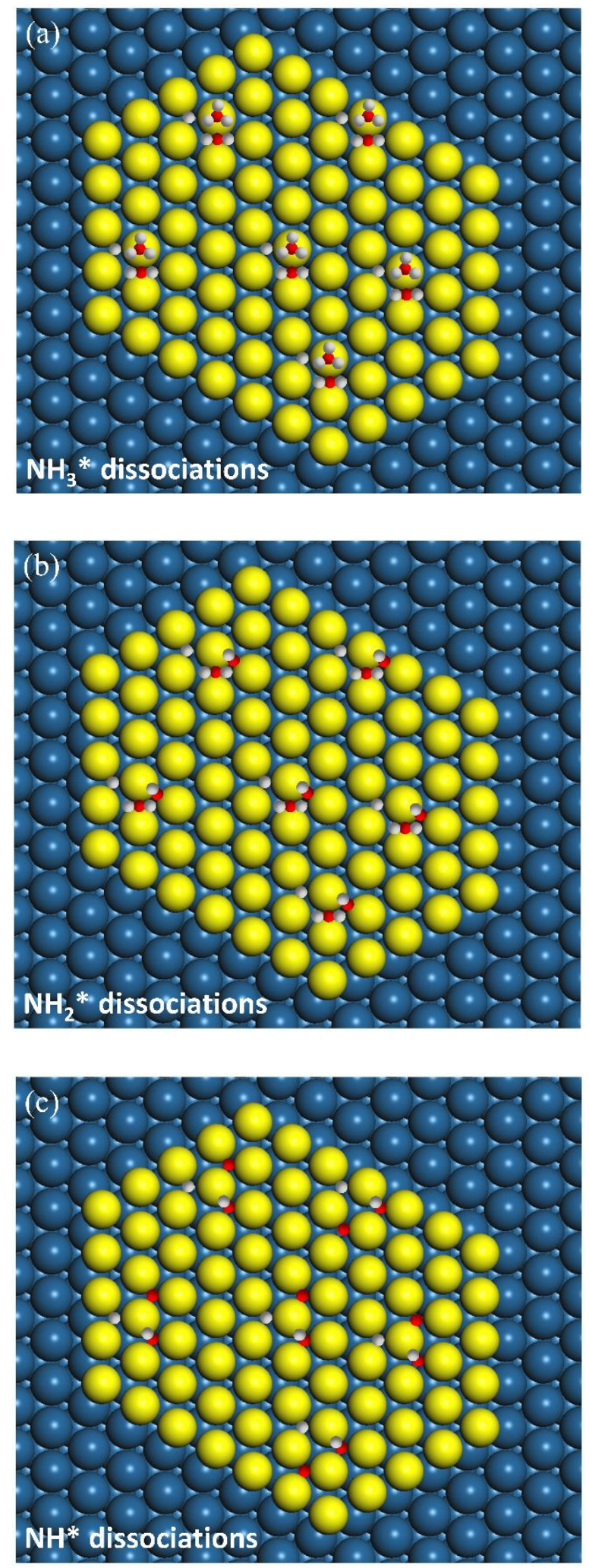

Figure S3. Schematics of the $\mathrm{NH}_{3}$ stepwise decomposition and corresponding reaction intermediates and active sites distribution on sub-monolayer surfaces of 79 guest atoms on FCC(111) host, considered in the KMC simulations. Panels from top to bottom are for the elementary steps of $\mathrm{NH}_{3}^{*}$ dissociation, $\mathrm{NH}_{2}^{*}$ dissociation, and $\mathrm{NH}^{*}$ dissociation, respectively. The yellow, dark blue, red and white spheres denote guest, host, $\mathrm{N}$ and $\mathrm{H}$ atoms, respectively. 


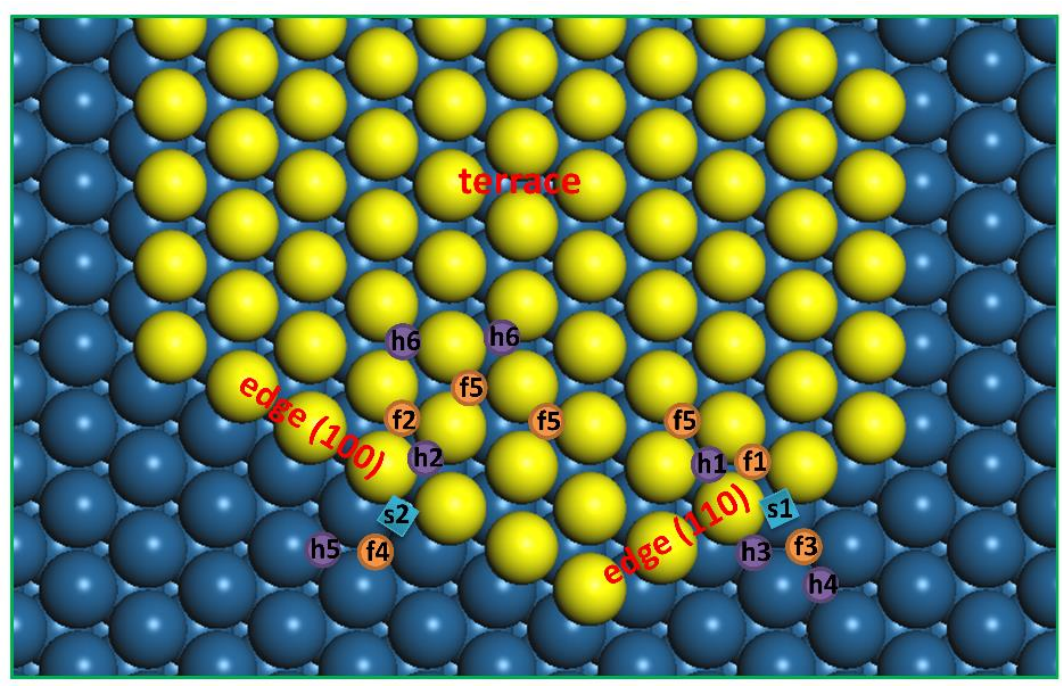

Figure S4. Schematic illustration of the reaction sites considered in the KMC simulations. The labels "f", "h", and "s" represent fcc hollow sites, hcp hollow sites, and step sites, respectively.

Table S2. N* diffusion steps, reaction sites and corresponding original/rescaled $\mathrm{N}^{*}$ diffusion barriers in KMC simulations. The sites refer to the labels shown in Fig. S4.

\begin{tabular}{cccc}
\hline No. & Reaction & Sites & Barriers (Original/Rescaled) \\
\hline 1 & $\mathrm{~N}^{*}$ diffusion & $\mathrm{f} 1, \mathrm{~s} 1$ & $0.81 / 1.4 \mathrm{eV}$ \\
2 & $\mathrm{~N}$ diffusion & $\mathrm{f} 5, \mathrm{~h} 6$ & $0.75 / 1.2 \mathrm{eV}$ \\
3 & $\mathrm{~N}$ diffusion & $\mathrm{f} 5, \mathrm{~h} 1$ & $0.75 / 1.15 \mathrm{eV}$ \\
4 & $\mathrm{~N}^{*}$ diffusion & $\mathrm{h} 2, \mathrm{~s} 2$ & $1.21 / 1.6 \mathrm{eV}$ \\
5 & $\mathrm{~N}$ diffusion & $\mathrm{f} 1, \mathrm{f} 2$ & $0.47 / 1.1 \mathrm{eV}$ \\
6 & $\mathrm{~N}$ diffusion & $\mathrm{h} 1, \mathrm{f} 2$ & $0.47 / 0.95 \mathrm{eV}$ \\
7 & $\mathrm{~N}$ diffusion & $\mathrm{f} 4, \mathrm{~s} 2$ & $0.36 / 0.7 \mathrm{eV}$ \\
\hline
\end{tabular}




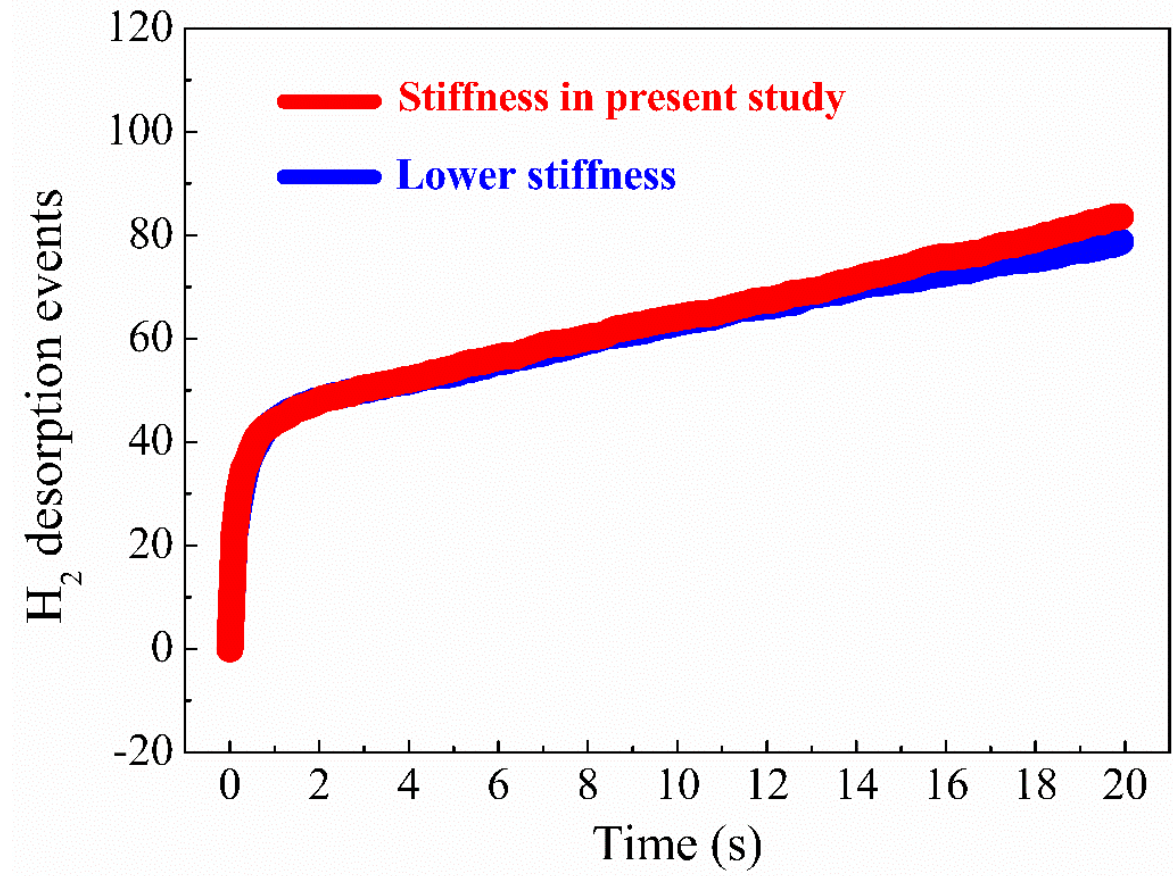

Figure S5. Comparison of KMC simulated $\mathrm{H}_{2}$ desorption rate on bimetallic $\mathrm{Ni} / \mathrm{Pt}$ surface between stiffness in the resent work and lower stiffness. The rates are averaged from $20 \mathrm{KMC}$ simulations at $673 \mathrm{~K}$ and $1.3 \times 10^{-3}$ bar.

\section{References}

(1) Abild-Pedersen, F.; Greeley, J.; Studt, F.; Rossmeisl, J.; Munter, T.; Moses, P. G.; Skulason, E.; Bligaard, T.; Nørskov, J. K. Scaling Properties of Adsorption Energies for Hydrogen-Containing Molecules on Transition-Metal Surfaces. Phys. Rev. Lett. 2007, 99, 016105.

(2) Guo, W.; Vlachos, D. G. Patched Bimetallic Surfaces are Active Catalysts for Ammonia Decomposition. Nat. Commun. 2015, 6, 8619. 